\title{
Pheochromocytoma: a retrospective study from a single center
}

\author{
Neuza Alves Soares ${ }^{1}$, Mariana Teixeira Pinto Ferreira Pacheco ${ }^{1}$, Manuel Joao Rocha Ferreira Rodrigues \\ De Sousa ${ }^{2}$, Mariana Lopes Matos ${ }^{1}$, Susana Alexandra Lourenco Ferreira ${ }^{1}$ \\ ${ }^{1}$ Internal Medicine Department, Centro Hospitalar Universitario de Sao Joao, Porto, Portugal; 2Surgeon MaxiloFacial \\ Department, Centro Hospitalar Universitario de Sao Joao, Porto, Portugal \\ E-mail: neuzasoares13@hotmail.com
}

Objectives. Pheochromocytoma (PCC) is a neuroendocrine tumor derived from chromaffin tissue more frequently found in the adrenal medulla. Many discoveries over the last decade have significantly improved our understanding of PCC.

Methods. We retrospectively reviewed all patients with a histological diagnosis of PCC at the Centro Hospitalar Universitario de Sao Joao, a tertiary and university hospital in Oporto, Portugal, between January 2009 and December 2017.

Results. The study group included 33 patients. In most cases the diagnosis was suspected with more than half of patients presenting with hypertension and the third diagnosed during the workup of an adrenal incidentaloma. About half of the patients was referred for genetic testing and 6 patients had a positive inherited susceptibility genetic pathogenic variant associated with classic cancer predisposition syndromes and also associated with newly described genes. In the incidentaloma group, genetic testing was performed in $3(9 \%)$ patients with only 1 positive result. In the suspected group, 15 (45\%) genetic tests were performed.

Conclusions. In contrast to other studies, where only a minority of patients with PCC were referred for genetic counselling, in our study $54 \%$ of patients was referred for genetic testing. This study suggests that clinicians were correctly recognizing the need to refer young patients and patients with positive family history. However, opportunities for genetic testing are frequently missed due to low referral rates in patients with apparently sporadic PCC, particularly older than 30 years old. It is imperative that all the providers involved in the multidisciplinary care of patients with pheochromocytomas are aware of the genetic disorders associated with these unique tumors.

Key words: pheochromocytoma, incidentaloma, metanephrines, catecholamines

Pheochromocytoma (PCC) is a neuroendocrine tumor derived from chromaffin tissue of the adrenal medulla, but it can also be derived from sympathetic of thorax, abdomen, pelvis or parasympathetic ganglia in the neck, and the base of the skull, called paraganglioma (PGL) (Davison et al. 2018) The WHO Classification of Tumours of Endocrine Organs ( $4^{\text {th }}$ Edition, 2017) defined metastatic tumor as the occurrence of metastasis in non-chromaffin organs.

The incidence of PCC/PGL is rare, 2-8 per million, and the mortality and morbidity rates are as low as $0-2 \%$ when submitted to surgical resection (Davison et al. 2018). However, as these tumors share the ability to synthesize and release catecholamines (dopamine, norepinephrine and epinephrine) and their metabolites (metanephrines), the consequences of undiagnosed or metastatic tumors may include uncontrolled hypertension and a result in severe cardiovascular morbidity and mortality (Berends et al. 2018). Symptoms vary according to the catecholamine that is secreted and which $a$ and/or $b$ receptor(s), as a result, stimulated. This symptom

Corresponding author: Neuza Alves Soares, Internal Medicine Department, Centro Hospitalar Universitario de Sao Joao, Alameda Prof. Hernani Monteiro, 4200-319, Porto, Portugal; phone: +351 936035821; e-mail: neuzasoares13@hotmail.com. 
variability contributes to the difficulty in establishing the diagnosis (Davison et al. 2018).

Many findings in the last decade and recent years have significantly improved our understanding of PCC/PGL (Alrezk et al. 2018). The sensitivity of biochemical tests and imaging techniques to detect PCC/PGL has substantially improved (Berends et al. 2018). Current clinical practice guidelines for the diagnosis of PCC/PGL state that total fractionated urine metanephrines or plasma-free metanephrines should be used as an initial biochemical screening for PPGL, as well as imaging studies to locate PCC/ PGL should be performed once when there is a clear biochemical evidence of the existence of the tumor (Lenders et al. 2014).

In addition, it is estimated that approximately $35-40 \%$ of PCC/PGL are hereditary. In the past, PCC/PGL was thought to be connected with genetic syndromes only in $10 \%$ of cases, based on the association with the classic cancer predisposition syndromes of neurofibromatosis type 1, von Hipppel-Lindau (VHL) syndrome and multiple endocrine neoplasia type 2 (MEN2). Recent advances also include the discovery of new related syndromes with PCC/PGL and their associated susceptibility genes due to germline pathogenic variants in over 12 susceptibility genes (Fishbein 2019).

The genotype-phenotype correlation demonstrated in many studies generally dictates the clinical presentations of the syndromic forms of PCC/PGL including the associated biochemical profile, tumor location, metastatic risk, and the overall prognosis for each clinical syndrome (Alrezk et al. 2018).

The main purpose of this study was to determine the experience of PCC in a tertiary and university hospital. We characterized the population, in which the diagnosis was clinically suspected versus the population, in which the diagnosis was made during the work up of incidentaloma versus the population, in which the diagnosis was made by screening. Besides, we analyzed the process and rate of referral for genetic testing.

\section{Subjects and methods}

Adult patients with a diagnosis of PCC were identified via a retrospective search of hospital records from a tertiary referral unit in Portugal (Centro Hospitalar Universitario de Sao Joao in Oporto) between January 2009 and December 2017.

All patients coded with neoplasm of adrenal gland in the International Classification of Diseases (ICD) version 9 since 2009 until 2016 and ICD version 10 in
2017 were eligible for inclusion.

The patients' electronic medical files were manually reviewed and those where PCC diagnosis was not confirmed by histological examination post tumor resection was excluded.

Clinical information collected included age of diagnosis, gender, tumor localization, size, bilaterally, multiplicity, biochemical profile, genetic testing, and presence of metastasis.

All data were consented by the Ethics Committee of the hospital.

Statistical analysis. Continuous variables were expressed as medians and interquartile ranges or sample range, as adequate. Categorical variables were output as counts and percentages. No imputation was made for missing data. As our study is a retrospective analysis, the cohort of patients did not result from random selection procedures. All statistics are

Table 1

Demographics and clinical characteristics at presentation of 33 patients with pheochromocytoma.

\begin{tabular}{|c|c|c|}
\hline Variables & $\begin{array}{l}\text { Patients } \\
\text { (n) }\end{array}$ & $\begin{array}{l}\text { Patients } \\
\text { (\%) }\end{array}$ \\
\hline \multicolumn{3}{|l|}{ Gender } \\
\hline Female & 19 & 57.6 \\
\hline Male & 14 & 42.4 \\
\hline \multicolumn{3}{|l|}{ Age at diagnosis } \\
\hline \multicolumn{3}{|l|}{ Distribution (years) } \\
\hline $18-29$ & 4 & 12.0 \\
\hline $30-39$ & 7 & 21.2 \\
\hline $40-49$ & 6 & 18.2 \\
\hline $50-59$ & 9 & 27.3 \\
\hline $60-69$ & 4 & 12.1 \\
\hline 70-79 & 3 & 9.1 \\
\hline \multicolumn{3}{|l|}{ Clinical Presentations } \\
\hline Hypertension & 14 & 42.4 \\
\hline Permanent & 7 & \\
\hline Permanent+paroxysmal & 5 & \\
\hline Paroxysmal & 2 & \\
\hline Asymptomatic & 11 & 33.3 \\
\hline Palpitations & 10 & 30.3 \\
\hline Headache & 10 & 30.3 \\
\hline $\begin{array}{l}\text { Classic triad } \\
\text { (headache+diaphoresis+tachycardia) }\end{array}$ & 3 & 9.0 \\
\hline Hypotension & 3 & 9.0 \\
\hline Abdominal pain & 2 & 6.0 \\
\hline Cardiogenic Shock & 2 & 6.0 \\
\hline
\end{tabular}


deemed to be descriptive. Statistical analysis was performed using SPSS Statistical software version 24, where $\mathrm{p}<0.05$ was deemed statistically significant.

\section{Results}

Patient characteristics. The study group included a total of 33 patients. Demographics and clinical characteristics are shown in Table 1. They were 19 (57\%) females with a median age of 47 years old (p25p75: 28-68).

In all cases, the presentation form was described and in the majority of cases there was a clinical suspicion of the diagnosis $(n=21 ; 63 \%)$ with more than half of patients presenting with some form of hypertension, sustained and/or associated with paroxysms. The classic triad of headaches, sweating, and palpitations was present only in $3(9 \%)$ patients and PCC crisis with cardiogenic shock was diagnosed in 2 (6\%) patients. In about a third ( $\mathrm{n}=11 ; 33 \%)$, PCC was diagnosed during in the workup of an adrenal incidentaloma (by abdominal ultrasound or computed tomography (CT) scan) and in 1 patient the diagnosis was made in a regular catecholamines screening performed due to a previously diagnosed familial syndrome.

The results of preoperative hormonal assays are given in Table 2. All patients had urine fractionated metanephrines and catecholamines test, but in only

\section{Table 2}

Preoperative hormonal data from 33 patients with pheochromocytoma.

\begin{tabular}{lcc}
\hline Variables & $\begin{array}{c}\text { Pathological } \\
\text { finding/total tested }\end{array}$ & $\begin{array}{c}\text { Pathological } \\
\text { finding (\%) }\end{array}$ \\
\hline Plasma & $3 / 8$ & 37.5 \\
Epinephrine & $4 / 80$ & 50.0 \\
Norepinephrine & $1 / 3$ & 33.3 \\
Dopamine & $3 / 7$ & 42.9 \\
Metanephrine & $2 / 7$ & 28.5 \\
Normetanephrine & & \\
Urinary & $21 / 28$ & 75.0 \\
Metanephrine & $26 / 28$ & 92.8 \\
Normetanephrine & $11 / 28$ & 39.3 \\
Epinephrine & $11 / 28$ & 39.3 \\
Norepinephrine & $2 / 27$ & 7.4 \\
Dopamine & $17 / 23$ & 73.9 \\
VMA & $5 / 5$ & 100.0 \\
\hline Chromogranin & & \\
\hline
\end{tabular}

Abbreviation: VMA - vanillylmandelic acid
7 (21\%) patients' plasma free metanephrines were performed. The total fractionated urine metanephrines sensitivity was $93 \%$. It was found that in $75 \%$ of them had a limit higher than 3 times normal. Plasma chromogranin A was elevated when performed, but it was only performed in 5 patients and the excretion of dopamine was only $6 \%$.

Radiologically, in all patients anatomical imaging, CT scan or magnetic resonance imaging were done. $26(78 \%)$ patients had additional functional imaging with ${ }^{123} \mathrm{I}$-metaiodobenzylguanidine (MIBG) scintigraphy scan. Of the 26 MIBG scans performed, 2 had false negative results. These 2 cases, clinically presented with paroxysmal hypertension and headache in the absence of sweating, tachycardia, hypotension, spells, hydro electrolytic disorders, or organ failure. Both had biochemical testing with urine fractionated metanephrines and catecholamines positivity, however neither of them was tested with plasma free metanephrines. There was no significant difference in tumor size between positive and false negative MIBG groups $(\mathrm{p}=0.15)$ and tumor size did not predict MIBG positivity $(\mathrm{p}=0.19)$. Additionally, ${ }^{18} \mathrm{~F}$-positron emission tomography (PET) scan was performed in 3 (9\%) patients with metastatic detection at presentation in 1 case (abdominal metastasis) and this is the only patient who passed away within 5 years after diagnosis of PCC.

More diagnoses were made over the study period, with the largest relative increase in age-specific in patients $>75$ years compared to the first 5 years of the study period. Throughout the study period, the prevalence was higher among individuals aged 50-74 years.

Genetic testing. About half of patients $(\mathrm{n}=18 ; 54 \%)$ was referred to genetic testing. Inherited susceptibility related to known genetic pathogenic variants was observed in $6(33 \%)$ patients and four of them (22\%) had a classic cancer predisposition syndrome (2 had neurofibromatosis type 1,1 had VHL syndrome, 1 had MEN2). The other 2 had mutation in the Succinate Dehydrogenase Subunit (SDH) genes, SDHD and SDHB. The patient with VHL syndrome produced exclusively noradrenergic biochemical phenotype, norepinephrine and normetanephrine, and the patient with MEN2 and neurofibromatosis type 1 produced adrenergic biochemical phenotype, norepinephrine, and epinephrine or their respective metabolites, normetanephrine and metanephrine.

Presentation as an adrenal incidentaloma, clinical suspected or screening cases. When comparing the diagnosis made in the incidentaloma group, the clinical suspected cases and the screening group, 
some differences were found. Table 3 outlines the comparison between these groups.

Patients with incidentalomas were older than the other groups.

There were no significant differences in biochemical testing with urine fractionated metanephrines and catecholamines neither plasma free metanephrines. In all patients, there was a positive correlation between urine fractionated metanephrines and catecholamines levels and blood pressure.

In the incidental group, the genetic testing was performed in $3(27 \%)$ patients, only one with a positive test. In the suspected group, 15 (71\%) genetic testing was performed and 4 were positive.

Bilateral tumor was present in one patient (from suspected group with SDHD positive) and there was no multifocal tumor in our sample.

One patient (from suspected group and with SDHB positive) had metastatic disease at presentation, in two patients metastasis was later developed (one from suspected with positive genetic test and one from the screening group - genetic testing was not performed in this particular patient). Tumor recurrence was observed in 4 patients, two of whom presented the genetic form of the disease (SDHB and VHL genes).

\section{Discussion}

The present retrospective study confirms the wide spectrum of presentations of PCC and also indicates that hypertension and typical symptoms may not be present at all. The most characteristic clinic sign of this disease and the one of most frequently reported in the literature is hypertension, which may be only paroxysmal, but is usually permanent or permanent with paroxysms (Baguet et al. 2004). According to the literature, the sensitivity and specificity of the clinical triad is high (Baguet et al. 2004). However, in the present study, only 3 patients were described with it.
As described in the literature, our study shows that urinary metanephrines sensitivity is high and the excretion of dopamine is exceptional.

Although most diagnoses were made following clinical suspicion, the incidentaloma was also significantly prevalent, especially in older patients. Cornu et al. (2019) and other studies have reported that up to $15 \%$ of these tumors are incidentalomas. The presentation as an incidentaloma was much higher in our study (33\%). However, we included patients up to 2017 and the increasing use of imaging techniques during the workup of multiple common pathologic entities could probably explain this difference. The improvement in availability and accessibility of imaging techniques can clarify, at least partially, why the rate of incidentally discovered pheochromocytoma is increasing. In contrast, the high proportion of incidentalomas in our study was probably fundamental reason for the low rate of bilateral and multifocal tumors in our cohort.

The mean age of the screened group was significantly lower than that of the incidental group. This is consistent with the literature. Neumann et al. (2002) have found that younger age at presentation was significantly associated with germline mutation of MEN2 and VHL. Furthermore, Walther et al. (1999) have found that younger age was associated with the VHL missense mutation. This suggests earlier development of PCC in familiar disorders. Besides, the syndromic PCC is also more likely to be diagnosed earlier in the course of the disease due to biochemical surveillance testing in known genetic disorder patients.

There has been documented an association between germline mutations and atypical PCC, which is consistent with our study (Fishbein 2019). The patient with bilateral tumor, the patient with metastatic PCC at presentation, and one of the 2 patients, who later developed metastasis, were associated with genetic

Table 3

Comparison incidentaloma, suspected pheochromocytoma and screening cases.

\begin{tabular}{lccc}
\hline Variables & $\begin{array}{c}\text { Incidentaloma } \\
\mathbf{n}(\%)\end{array}$ & $\begin{array}{c}\text { Clinical suspicion } \\
\mathbf{n}(\%)\end{array}$ & $\begin{array}{c}\text { Screening } \\
(\mathbf{n})\end{array}$ \\
\hline Total of cases & $11(33.0 \%)$ & $21(63.0 \%)$ & 1 \\
Mean age & 58 & 39 & 26 \\
Genetic test performed & $3(27.0 \%)$ & $15(71.0 \%)$ & 1 \\
Positive genetic test & 1 & 5 & 1 \\
Positive urine free metanephrine & $9(81.8 \%)$ & $14(66.6 \%)$ & 1 \\
Positive urine catecholamines & $8(72.7 \%)$ & $11(52.4 \%)$ & 1 \\
Positive plasma free metanephrine & $6(54.5 \%)$ & $10(47.6 \%)$ & 1 \\
\hline
\end{tabular}


mutations. Besides, tumor recurrence was observed in 4 patients, 2 of them presented genetic mutations.

In addition, genetic identification provides valuable information that has paramount value, not only to establish the diagnosis, but also to assist in formulating management and treatment plans, as well as appropriate follow-up intervals that can guide consistent genetic counselling for each syndrome (Alrezk et al. 2018). Knowing if a patient carries a pathogenic variant in a susceptibility gene is important as it alters the surveillance and screening needed for the patient based on the associated tumor syndrome and it affects the clinical care of the relatives who may be asymptomatic carriers (Fishbein 2019). Knowledge regarding the genetic background of patients with PCC has the potential to improve management also by giving more accurate risk stratification. While most PCC has a low risk of malignancy, patients with SDHB mutations have higher risks of malignancy and conversely, patients with RET germline mutations have a much lower risk of malignancy (Chew et al. 2017).

Current genetic testing algorithms are based on both the 2014 Endocrine Society Clinical Practice Guidelines (Lenders et al. 2014) and on the 2014 American College of Medical Genetics (Bean and Bayrak-Toydemir 2014). Both guidelines recommend that all patients with PCC should be considered to perform genetic testing as part of their management depending on age of presentation, family history, syndromic features, tumor localization, bilaterally, multifocal, metastatic disease, and biochemical find- ings. Although in other studies (Mannelli 2009; Chew et al. 2017), only a minority of patients with PCC have been referred to genetic counselling, in our study $54 \%$ patients were referred to genetic testing. Besides, in literature genetic testing is not consensual in incidentalomas. Despite VHL mutations have been reported as one of the commonly seen mutation (Chew et al. 2017). Our study does not show these data. In this study, no genetic mutation was significantly more common, perhaps due to the small sample of patients.

Obviously, we have to take in account the limitations of the study, such as the small sample. Besides, our data suggests that physicians were correctly recognizing the need to provide genetic counselling to young patients and patients with positive family history. Nonetheless, they were less likely to test older sporadic PCC. Thus, there are still potentially significant missed opportunities for intervention, especially in older patients. The extent of genetic testing is influenced by several factors, including cost and the diagnostic algorithm employed for genetic study referral (Chew et al. 2017).

Clinicians need to be aware of the pleomorphic presentation of PCC since early identification can be life-saving. It is imperative that all the providers involved in the multidisciplinary care of patients with pheochromocytomas and paragangliomas are aware of the genetic disorders associated with these unique tumors. Opportunities for genetic testing are frequently missed due to low referral rates in patients with apparently sporadic PCC, particularly after 30 years old (Fishbein 2019).

\section{References}

Alrezk R, Suarez A, Tena I, Pacak K. Update of pheochromocytoma syndromes: genetics, biochemical evaluation, and imaging. Front Endocrinol (Lausanne) 9, 515, 2018.

Baguet JP, Hammer L, Mazzuco TL, Chabre O, Mallion JM, Sturm N, Chaffanjon P. Circumstances of discovery of phaeochromocytoma: a retrospective study of 41 consecutive patients. Eur J Endocrinol 150, 681-686, 2004.

Bean L, Bayrak-Toydemir P. American College of Medical Genetics and Genomics Standards and Guidelines for Clinical Genetics Laboratories, 2014 edition: technical standards and guidelines for Huntington disease. Genet Med 16, e2, 2014.

Berends AMA, Buitenwerf E, de Krijger RR, Veeger NJGM, van der Horst-Schrivers ANA, Links TP, Kerstens MN. Incidence of pheochromocytoma and sympathetic paraganglioma in the Netherlands: A nationwide study and systematic review. Eur J Intern Med 51, 68-73, 2018.

Chew WHW, Courtney E, Lim KH, Li ST, Chen Y, Tan MH, Chung A, Khoo J, Loh A, Soh SY, Iyer P, Loh LM, Ngeow J. Clinical management of pheochromocytoma and paraganglioma in Singapore: missed opportunities for genetic testing. Mol Genet Genomic Med 5, 602-607, 2017.

Cornu E, Belmihoub I, Burnichon N, Grataloup C, Zinzindohoue F, Baron S, Billaud E, Azizi M, Gimenez-Roqueplo AP, Amar L. Pheochromocytome et paragangliome [Phaeochromocytoma and paraganglioma]. Rev Med Interne 40, 733-741, 2019.

Davison AS, Jones DM, Ruthven S, Helliwell T, Shore SL. Clinical evaluation and treatment of phaeochromocytoma. Ann Clin Biochem 55, 34-48, 2018. 
Fishbein L. Pheochromocytoma/paraganglioma: Is this a genetic disorder? Curr Cardiol Rep 21, $104,2019$.

Lenders JW, Duh QY, Eisenhofer G, Gimenez-Roqueplo AP, Grebe SK, Murad MH, Naruse M, Pacak K, Young WF Jr; Endocrine Society. Pheochromocytoma and paraganglioma: an endocrine society clinical practice guideline. J Clin Endocrinol Metab 99, 1915-1942, 2014.

Mannelli M. Biochemistry, genetics and therapy of malignant pheochromocytomas. Ann Endocrinol (Paris) 70, 166-167, 2009.

Neumann HP, Bausch B, McWhinney SR, Bender BU, Gimm O, Franke G, Schipper J, Klisch J, Altehoefer C, Zerres K, Januszewicz A, Eng C, Smith WM, Munk R, Manz T, Glaesker S, Apel TW, Treier M, Reineke M, Walz MK, Hoang-Vu C, Brauckhoff M, Klein-Franke A, Klose P, Schmidt H, Maier-Woelfle M, Peczkowska M, Szmigielski C, Eng C; Freiburg-Warsaw-Columbus Pheochromocytoma Study Group. Germ-line mutations in nonsyndromic pheochromocytoma. N Engl J Med 346, 1459-1466, 2002.

Walther MM, Reiter R, Keiser HR, Choyke PL, Venzon D, Hurley K, Gnarra JR, Reynolds JC, Glenn GM, Zbar B, Linehan WM. Clinical and genetic characterization of pheochromocytoma in von Hippel-Lindau families: comparison with sporadic pheochromocytoma gives insight into natural history of pheochromocytoma. J Urol 162, 659-664, 1999.

WHO Classification of Tumours of Endocrine Organs, WHO Classification of Tumours, 4th Edition, Volume 10 (Eds. Lloyd RV, Osamura RY, Kloppel G, Rosai J), 2017. 